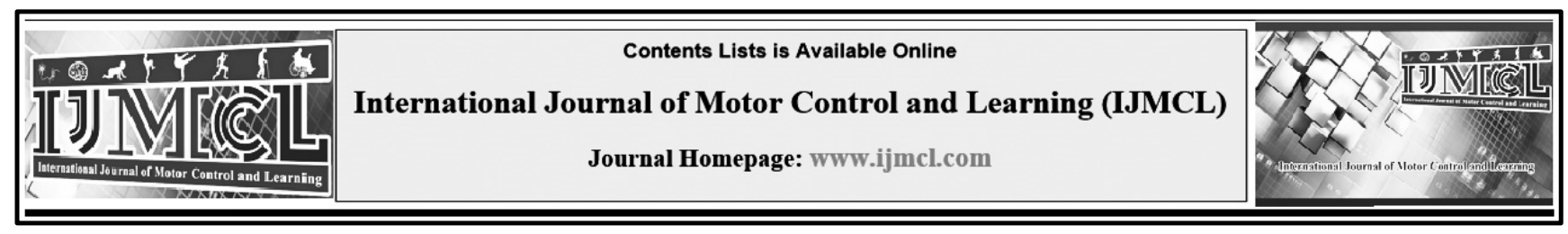

\title{
Perceived Motor Clumsiness: A Study of Young College Students
}

\author{
Carl Gabbard ${ }^{\mathrm{a}^{*}}$, Rachel Sullivan $\underline{\underline{b}}$, Meagan Albosta $\underline{\underline{b}}$, Jihye Lee $\underline{\underline{b}}$
}

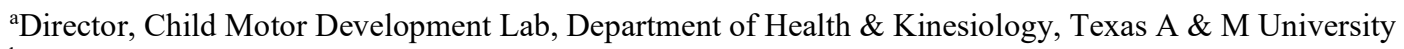

${ }^{\mathrm{b}}$ Department of Health \& Kinesiology, Texas A \& M University

\begin{tabular}{|c|c|}
\hline Keywords & Abstract \\
\hline Developmental Coordination Disorder & Background/Objective: This study surveyed the probable incidence of \\
\hline Adult Incidence & $\begin{array}{l}\text { Developmental Coordination Disorder (DCD), a medical condition marked by poor } \\
\text { motor coordination and clumsiness, in college-aged students. } \\
\text { Methods: A total of } 4,014 \text { individuals at Texas A\&M University, aged } 18-23(40 \% \\
\text { males and } 60 \% \text { females), completed the Adolescents and Adults Coordination }\end{array}$ \\
\hline $\begin{array}{l}\text { Carl Gabbard, } \\
\text { Director, Child Motor Development Lab }\end{array}$ & Questionnaire (AAC-Q) using Qualtrics, a web-based survey procedure. \\
\hline Dept. of Health \& Kinesiology & Results/Conclusions: Results indicated that about $7 \%$ of individuals fell into the \\
\hline $\begin{array}{l}\text { TAMU } 4243 \\
\text { College Station, TX 77843-4243 }\end{array}$ & category of 'probable' or 'likely' to have DCD. Although marginal, age differences \\
\hline $\begin{array}{l}\text { College Station, TX } 77843-4243 \\
\text { (979) } 845-1277\end{array}$ & were found to be significant with participants below 20 years old having more \\
\hline Fax-847-8987 & difficulty (greater perceived clumsiness) than those 20 years and older. In regard to \\
\hline E-mail: c-gabbard@tamu.edu & gender, 5 of the 12 total items were statistically significant with females having a \\
\hline Received: 2019/08/17 & greater proportion of perceived clumsiness than males in 4 out of the 5 questions. \\
\hline Accepted: 2019/10/30 & $\begin{array}{l}\text { That is, temales indicated more difticulty with gross motor skills, such as learning } \\
\text { to drive or to ride a bike, whereas males indicated more difficulty with fine motor }\end{array}$ \\
\hline Published: 2019/11/12 & $\begin{array}{l}\text { tasks, such as handwriting, and completing tasks requiring fine detail. Interestingly, } \\
\text { the } 7 \% \text { clumsiness level found here is similar to the well-documented level of } 6 \% \\
\text { found in children; therefore, giving some credence to the likelihood that children } \\
\text { may not 'simply mature out of the condition.' This was a preliminary study and } \\
\text { future research needs to examine actual (rather than perceived level) of DCD. }\end{array}$ \\
\hline
\end{tabular}

\section{Introduction}

Developmental Coordination Disorder (DCD) is a condition marked by poor motor coordination and clumsiness. It describes motor impairment in the absence of any neurological disease, known physical disorder, mental retardation, and / or low IQ. Through DCD, clumsiness can be classified as a medical disorder. It has been shown that DCD interferes with a wide variety of behaviors and skills. Studies indicate that it affects such items as academic achievement, engaging in sports activities, and daily living skills, such as dressing, tying shoelaces and brushing teeth. Individuals with DCD have been found to have a pronounced difficulty in internal (forward) modeling, suggesting that people with this disorder over- or underestimate the planning and execution aspect of movement (Wilson, Ruddock, Smits-Engelsman, Polatajko, \& Blank, 2013). It should be noted, however, that most research to date has been done with children.

The prevalence of DCD has been estimated to be as high as $6 \%$ of children from ages 5-11 years, with $2 \%$ being severely affected (Zwicker, 
Missiuna, Harris, \& Boyd, 2012). It used to be thought that a child grew out of the disorder by adolescence. However, it is now recognized that the signs and symptoms of DCD can persist well into adolescence and adulthood (Hands, Licari, \& Piek, 2015). That brings us to the present study. A recent review done by Tal-Saban and Kirby (2018) reports that between 30 and $70 \%$ of children diagnosed with DCD continue to have difficulties with daily functioning that persist into adulthood. It has also been reported that DCD may interfere with daily functioning in both academic and nonacademic abilities among adults (Tal-Saban, Ornoy, \& Parush, 2018). Some of these aspects include social relationships, employment, and daily living skills such as personal care, walking, and driving a car (Gagnon-Roy, Jasmin, \& Camden, 2016). Speculatively, one possible underlying factor associated with movement efficiency is the finding that those with DCD have higher levels of fatigue compared to typically developing individuals (Thomas \& Christopher, 2018). In regard to walking, one study found that individuals with DCD revealed greater inconsistencies in foot placement and gait patterns compared to those without DCD (Wilmut, Gentle, \& Barnett, 2017). An analysis of a longitudinal study and a recent review has shown that quality of life, participation in activities, and life satisfaction of adults and adolescents with DCD is lower than individuals without the disorder (Tal-Saban, Ornoy, \& Parush, 2014; Tal-Saban \& Kirby, 2018).

Whereas some information is available, as highlighted here, currently little is known about the prevalence of DCD in young adults. To gain more information on this, the purpose of our preliminary study was to estimate the prevalence of DCD among college-age students. With this information, we wished to determine if there is a need for special motor enhancement classes and opportunities for these students to be offered by the university.

\section{Method}

\section{Instrument}

Data were collected using the Adolescents and Adults Coordination Questionnaire (AAC-Q) (Tal-Saban, Ornoy, Grotto, \& Parush, 2012). This survey is reported by the authors to be reliable and valid. Studies using the AAC-Q have also found it to be valid and reliable (Tal-Saban, Zarka, Grotto, Ornoy, \& Parush, 2012) (Tal-Saban et al., 2018). The AAC-Q consists of 12 questions asking participants about their perceived level of motor ability in a variety of tasks. For the purpose of our study, scoring based on a 5-point Likert scale (1-5). The responses of never, occasionally, often, frequently, and always were used respectively. This resulted in a possible total score of 60. For our study, we mainly looked at participants who answered "often", "frequently" or "always". These answers were then combined into a group of participants categorized as having difficulty. Probable DCD meant being in the top 50\% of scores with a score of 30 to 35 and likely DCD meant being in the top $60 \%$ of scores with a score of 36 and above derived from the suggestions of (Kirby, Edwards, Sugden, \& Rosenblum, 2010). 


\section{Participants and Procedure}

The target population for the survey was university students aged 18-23 years. Survey information was collected using Qualtrics, an online survey instrument. The online survey was created by converting the AAC-Q to a digital format, which to our knowledge had never been done before. The survey was then distributed university-wide via the student directory. Permission through the university to deliver the survey was given as well as overall approval by the university Institutional Review Board.

The bulk email was sent to 47,150 email addresses which consisted of 53\% males and $47 \%$ females. We had a total of 4,014 complete survey responses which represent $12 \%$ of the total possible; $60 \%$ were female and $40 \%$ male. Fifteen (15) $\%$ of respondents were below the age of 20 and $86 \%$ were age 20 or above.

Table 1 shows the demographics of the sample.

\section{Results}

\section{Data Analyses}

Data were analyzed first using frequency analysis to determine proportions and percentages. For proportion comparisons, we used Chi-square and for mean comparisons an Age (2) x Gender (2) analysis of variance. The ANOVA yielded a significant main effect for Gender, $F(12,3999)=$ 95.70, $p<.05$, and Age, $F(12,3999)=1.87, p<.05$. Post hoc analyses revealed that, overall, females had significantly higher mean scores $(M=1.79$, $\mathrm{SD}=0.47)$ than males $(M=1.61, \mathrm{SD}=0.42)$. In regard to Age, those below 20 years old had higher mean scores $(M=1.75, S D=0.48)$ than those that were equal to or greater than 20 years of age $(M=$ 1.70, $S D=0.45)$. In addition, there was no significant interaction between Gender and Age. For ease of readability, proportion results will be described with the following passages.

Table 1 shows the top five questions for the last three responses (often, frequently, always) regarding mean score and percentage.

Regarding motor related (clumsiness), arguably Questions 2 and 11 would clearly fit that domain. These questions had a mean score of 2.16 and 1.90 and a last 3 response rate of $27 \%$ and $22 \%$ respectively. Keep in mind that a higher mean score represents greater perceived clumsiness. Question 7 , relating to 'orienting in space', with a mean score of 1.94 and a response rate of $22 \%$, also has an obvious aspect of motor behavior. This aspect of motor clumsiness could potentially be detrimental to students having to navigate campus and the crowds of people they encounter as well as crowded environments in the community. In addition, Question 7 also hints at memory, which could have something to do with attention. The two remaining questions, Question 6 with the highest mean score (2.24) regarding 'time management', and Question 9 (2.14), 'losing or forgetting things', relate to memory and attention. One could argue that as observed with individuals with ADHD, this absent-mindedness regarding time is important. Both these questions ( $6 \& 9$ ) being in the top 5 complements previous research that there may be a comorbidity factor among those with DCD and ADHD (Smits-Engelsman, Jover, Green, 
Ferguson, \& Wilson, 2017). Although a lot of the comorbidity research has been done on children, since recent research is reporting the persistence of
DCD into adulthood, it could be assumed that the comorbidity with ADHD would persist as well.

Table 1. Top Five Questions for Highest Percentages of Last 3 Responses (Often, Frequently, Always).

\begin{tabular}{|c|c|c|c|c|}
\hline Rank & Question \# & Question & $\begin{array}{l}\text { Total Mean } \\
\text { Score }\end{array}$ & \% Last 3 Responses \\
\hline 1 & Q6 & $\begin{array}{l}\text { I have difficulty with time management like arriving on time, finishing assignments, } \\
\text { finishing exams or other timed activities within the allotted time, I plan my day but } \\
\text { do not finish everything I planned. }\end{array}$ & $2.24 *$ & 31.60 \\
\hline 2 & Q2 & $\begin{array}{l}\text { I tend to be clumsy, fall often, drop items or bump into objects like closely packed } \\
\text { furniture, crowded spaces, narrow passageways }\end{array}$ & 2.16 & 27.10 \\
\hline 3 & Q9 & $\begin{array}{l}\text { I frequently lose or forget things like: writing implements, coats, umbrellas, books, } \\
\text { glasses, keys, cell phone, wallet. }\end{array}$ & 2.14 & 25.20 \\
\hline 4 & Q11 & $\begin{array}{l}\text { I have difficulty with handwriting like: copying quickly from the board, writing } \\
\text { legibly, taking notes during class, I write slowly. }\end{array}$ & 1.90 & 22.40 \\
\hline 5 & Q7 & $\begin{array}{l}\text { I have difficulty orientating in space like getting lost easily, difficulty learning how } \\
\text { to get to a new place, difficulty recognizing familiar driving routes, problems using } \\
\text { a road map, difficulty finding your car in a car park, difficulty exiting a mall where } \\
\text { I entered. }\end{array}$ & 1.94 & 21.70 \\
\hline
\end{tabular}

*higher value represents greater perceived clumsiness.

Table 2. Top Questions of Difficulty by Gender.

\begin{tabular}{cccc}
\hline & Male & & Female \\
\hline Questions & Mean & Questions & Mean \\
Q6 & 2.22 & Q2 & 2.43 \\
Q11 & 2.13 & Q6 & 2.26 \\
Q9 & 2.02 & Q9 & 2.21 \\
Q2 & 1.74 & Q7 & 2.15 \\
Q10 & 1.66 & Q10 & 1.85 \\
\hline
\end{tabular}

Table 2 shows mean values for the top 5 Questions by Gender. As noted in the results, there was a significant overall difference with females having higher overall mean scores. Four out of the 5 top 5 questions for males and females were the same although ranked in a different order. The questions that differed for each gender were Question 11 relating to 'difficulty with handwriting' for males and Question 7 for females relating to 'space orientation'. In no particular order, the other top 5 questions related to clumsiness $(\mathrm{Q} 2)$, time management $(\mathrm{Q} 6)$, losing or forgetting things (Q9), and learning new sports (Q10). The highest mean score question for females was \#2 (2.43) with 'clumsiness' and the highest score for males was Question 6 (2.22), time management. Question 6 relating to time management, was the only question out of the top 5 not to have a gender difference.

Table 3 shows questions with Gender differences by a proportion of the sample.

Results for four of the 5 questions show that there was a significant difference with females having a greater proportion than males. Question 11 regarding handwriting is the only question showing males with a higher proportion of perceived clumsiness than females with a chisquared value of 6.356 and a p-value of .04. Interestingly, although not in the same order, these 
are the same five questions shown in Table 1 for the top 5 questions for the last three responses

In regard to Age, as noted earlier, ANOVA analysis found that participants below 20 years old had higher mean scores than the age group that was equal to or greater than 20 years old. This meant that those 20 years of age $(m=1.75)$ had more difficulty (greater perceived clumsiness) than those 20 years and older $(m=1.70)$. One could argue however, that the difference in mean scores between age groups, although statistically significant, was marginal. In summary, results found that gender $(p=.00)$ had a greater effect on perceived clumsiness scores than Age $(p=.034)$.

Finally, we come to the primary question at hand. What was the estimate of DCD in young adults? Table 4 shows the number and percent of those with probable and likely DCD.

Table 3. Questions with Gender differences by a proportion of the sample.

Q\# Question $\quad$ \# Male \# Female $\quad X^{2}$ P-value

2 I tend to be clumsy, fall often, drop items or bump into objects like closely packed furniture, crowded spaces, narrow passageways 180

I have difficulty with time management like arriving on time, I planned.

I have difficulty orientating in space like getting lost easily, difficulty learning how to get to a new place, difficulty recognizing

7 familiar driving routes, problems using a road map, difficulty finding your car in a car park, difficulty exiting a mall where I entered.

Table 4. Number and percent of those with probable and likely DCD.

\begin{tabular}{ccc}
\hline & Number & Percent $(\%)$ \\
\hline Probable DCD $(30 \leq \mathrm{x} \leq 35)$ & 213 & 5.31 \\
Likely DCD $(\geq 36)$ & 63 & 1.57 \\
Total $(N=4014)$ & 276 & 6.88 \\
\hline
\end{tabular}


Keep in mind that based on the recommendations of (Kirby et al., 2010), we arbitrarily used the scores $50 \%$ and $60 \%$ for probable and likely DCD. The percentage of those with probable and likely DCD were $5.1 \%$ and $1.6 \%$ respectively for a total of approximately $7 \%$. Interestingly, this matches the latest findings where the prevalence of DCD was nearly $6 \%$ in children 5-12 years old (Farmer, Echenne, Drouin, \& Bentourkia, 2017). From these overall findings, we might surmise that the prevalence of DCD "may" persist into young adulthood. Obviously, our study had a significant limitation given that we did not actually assess DCD. However, a significant relationship between actual and perceived DCD was reported by Kirby et al. (2010) and Tal-Saban et al. (2012).

\section{References}

1. Farmer, M., Echenne, B., Drouin, R., \& Bentourkia, M. (2017). Insights in developmental coordination disorder. Current Pediatric Reviews, 13(2), 111-119. doi:10.2174/1573396313666170726113550

2. Gagnon-Roy, M., Jasmin, E., \& Camden, C. (2016). Social participation of teenagers and young adults with developmental co-ordination disorder and strategies that could help them: Results from a scoping review. Child: Care, Health and Development, $\quad 42(6), \quad 840-851$. doi:10.1111/cch.12389

3. Hands, B., Licari, M., \& Piek, J. (2015). A review of five tests to identify motor coordination difficulties in young adults. Research in Developmental Disabilities, 41-42, 40-51. doi:10.1016/j.ridd.2015.05.009

4. Kirby, A., Edwards, L., Sugden, D., \& Rosenblum, S. (2010). The development and standardization of the adult developmental co-ordination disorders/dyspraxia checklist (ADC). Research in Developmental Disabilities, 31(1), 131-139. doi:10.1016/j.ridd.2009.08.010
5. Smits-Engelsman, B. C. M., Jover, M., Green, D., Ferguson, G., \& Wilson, P. (2017). DCD and comorbidity in neurodevelopmental disorder: How to deal with complexity? doi://doiorg.ezproxy.library.tamu.edu/10.1016/j.humov.201 7.02.009

6. Tal-Saban, M. T., Ornoy, A., Grotto, I., \& Parush, S. (2012). Adolescents and adults coordination questionnaire: Development and psychometric properties. The American Journal of Occupational Therapy: Official Publication of the American Occupational Therapy Association, 66(4), 406-413. doi:10.5014/ajot.2012.003251

7. Tal-Saban, M., Zarka, S., Grotto, I., Ornoy, A., \& Parush, S. (2012). The functional profile of young adults with suspected developmental coordination disorder (DCD) doi://doiorg.ezproxy.library.tamu.edu/10.1016/j.ridd.2012.0 6.005

8. Tal-Saban, M., Ornoy, A., \& Parush, S. (2014). Young adults with developmental coordination disorder: A longitudinal study. The American Journal of Occupational Therapy: Official Publication of the American Occupational Therapy Association, 68(3), 307-316. doi:10.5014/ajot.2014.009563

9. Tal-Saban, M., \& Kirby, A. (2018). Adulthood in developmental coordination disorder (DCD): A review of current literature based on ICF perspective. Current Developmental Disorder Reports, doi:10.1007/s40474-018-0126-5

10. Tal-Saban, M., Ornoy, A., \& Parush, S. (2018). Success in adults with probable developmental coordination disorder using structural equation modeling. The American Journal of Occupational Therapy: Official Publication of the American Occupational Therapy Association, 72(2), 7202205010p8. doi:10.5014/ajot.2018.022012

11. Thomas, M., \& Christopher, G. (2018). Fatigue in developmental coordination disorder: An exploratory study in adults. Fatigue: Biomedicine, Health \& Behavior, 6(1), 41-51. doi:10.1080/21641846.2018.1419564

12. Wilmut, K., Gentle, J., \& Barnett, A. L. (2017). Gait symmetry in individuals with and without developmental coordination disorder. Research in Developmental Disabilities, 60, 107-114. doi:10.1016/j.ridd.2016.11.016

13. Wilson, P. H., Ruddock, S., Smits-Engelsman, B., Polatajko, H., \& Blank, R. (2013). Understanding performance deficits in developmental coordination disorder: A meta-analysis of recent research. Developmental Medicine and Child Neurology, 


\section{Original article}

IJMCL 2019; 1(2) 3-9

55(3), 217-228. doi:10.1111/j.1469-

8749.2012.04436.x

14. Zwicker, J. G., Missiuna, C., Harris, S. R., \& Boyd, L. A. (2012). Developmental coordination disorder: A review and update. European Journal of Pediatric Neurology: EJPN: Official Journal of the European Pediatric Neurology Society, 16(6), 573-581. doi:10.1016/j.ejpn.2012.05.005 